\title{
Gastrointestinal anastomosis using a new lumen-apposing metal stent for biliary drainage is a good option in the palliative setting
}

A 74-year-old woman was hospitalized in August 2017 for altered performance status and obstructive cholangitis due to the recurrence of an adenocarcinoma involving the head of the pancreas that had been resected 2 year previously. Disease recurrence was locoregional and causing complete stenosis of the afferent loop, which prevented access to the biliary-digestive anastomosis using an endoscope. This stenosis was responsible for the accumulation of bilirubin in the afferent loop and distension of the biliary ducts ( $\triangleright$ Fig. $\mathbf{1}$ a,b). Antibiotics were started and a percutaneous drain was placed with technical success; however, the patient's bilirubin level remained high $(200 \mu \mathrm{mol} / \mathrm{L})$ despite a second attempt at drainage on day 3.
After multidisciplinary discussion, it was decided to perform endoscopic drainage, given the age and the performance status of the patient, which made her not fit for a surgical approach (performance status 4). A linear echoendoscope (EG 3670 URK; Pentax, France) was placed in the stomach. The distended afferent loop, located near the gastric wall, was easily identified and endoscopic ultrasound (EUS)-guided placement of an AXIOS stent (15-mm diameter; Boston Scientific) allowed a connection to be created between the stomach and the afferent loop, thereby achieving biliary drainage ( $\nabla$ Fig. $\mathbf{1} \mathbf{c}-\mathbf{i})$. There were no early or late complications related to this procedure.
The patient's bilirubin level decreased progressively, returning to the normal range within 3 months and was stable during the next 3 months before beginning to increase again ( $\triangleright$ Fig. 2 , - Video 1). During this time, the patient felt better and her performance status improved (performance status 2) such that, 5 months after endoscopic drainage, she was able to resume feeding and walking, which improved her moral.

At month 7, icterus recurred due to hepatic hilum obstruction; however, this time, the afferent loop was directly accessible by passing the endoscope through the AXIOS stent. Extrinsic stenosis of hepatic hilum was confirmed by cholangiography. Metal and plastic stents were placed between the intrahe-

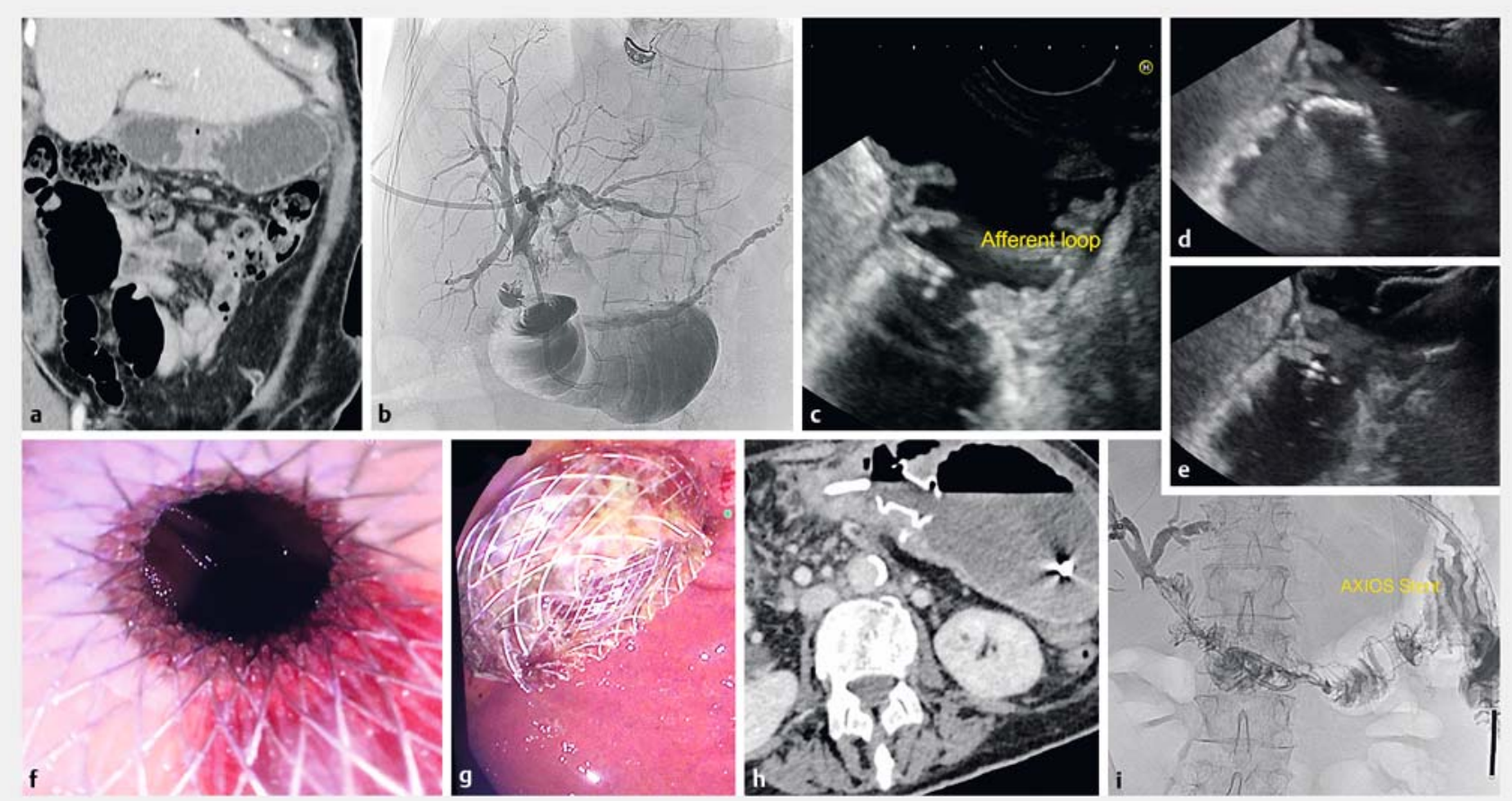

- Fig. 1 Endoscopic biliary drainage in an elderly woman with recurrent pancreatic adenocarcinoma causing stenosis of the afferent loop. a, b Radiographic images showing the dilated intestinal loop and biliary ducts. c, d, e Lumen-apposing metal stent (LAMS) placement via endoscopic ultrasound guidance. $\mathbf{f}, \mathbf{g}$ Endoscopic images of the LAMS in position. $\mathbf{h}, \mathbf{i}$ Radiographic images showing the LAMS allowing communication between the afferent intestinal loop and stomach. 


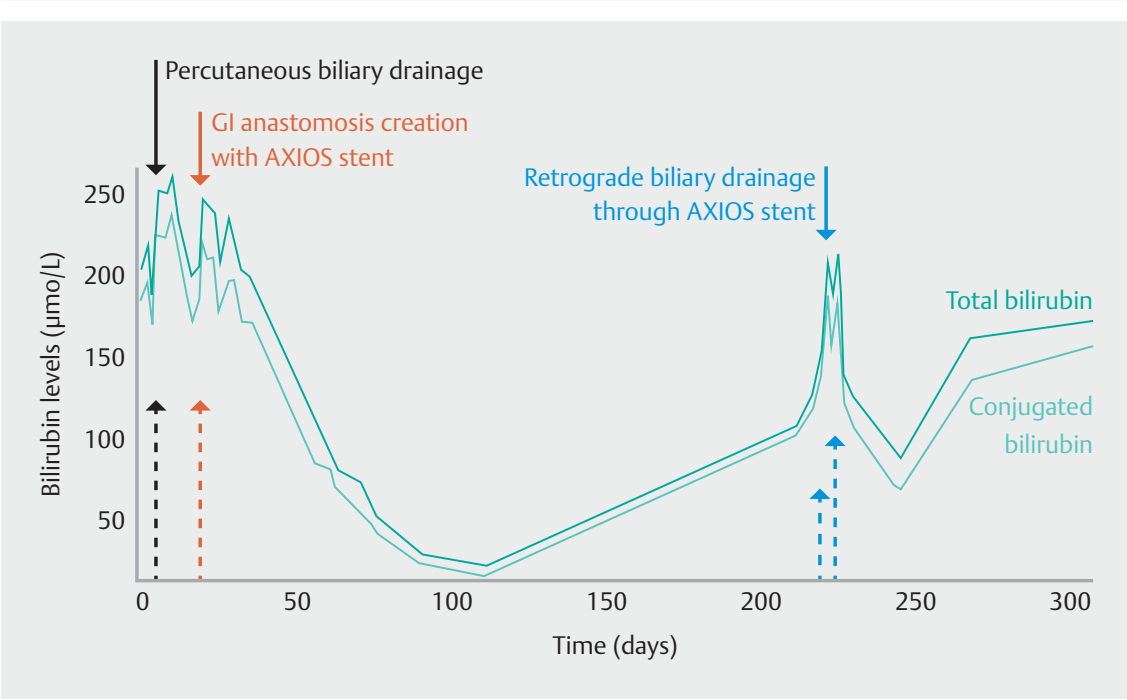

- Fig. 2 Total and conjugated bilirubin levels over the time following biliary drainage by placement of a lumen-apposing metal stent.

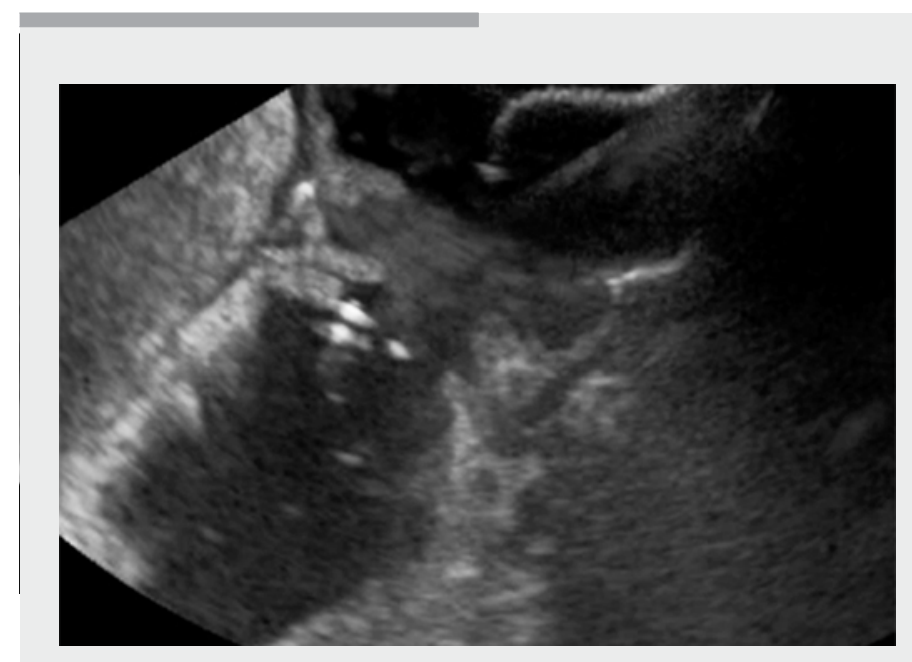

$\checkmark$ Video 1 Endoscopic biliary drainage in an elderly woman with recurrent pancreatic adenocarcinoma by placement of a lumen-apposing metal stent between the stomach and the afferent loop, which led to a fall in her bilirubin and clinical improvement for several months.

patic bile ducts and the afferent digestive loop, allowing a transient improvement in the cholestasis (> Fig. 2 ).

The patient died of her cancer 3 months later, meaning she survived a total of 9 months from the first biliary drainage. This case shows the feasibility of biliary drainage by creation of an endoscopic gastrointestinal anastomosis in the con-
The authors

N. Soukaïna Chawki ${ }^{1}$, Bertrand Leroy ${ }^{2}$, Bachir Hag $^{3}$, Xavier Roblin ${ }^{1}$, Jean-Marc Phelip ${ }^{1,4}$, Nicolas Williet ${ }^{1,4}$

1 Department of Hepato-gastro-enterology, University Hospital of Saint-Etienne, SaintPriest-en-Jarez, France

2 Department of General Surgery, University Hospital of Saint-Etienne, Saint-Priest-enJarez, France

3 Department of Radiology, University Hospital of Saint-Etienne, Saint-Priest-enJarez, France

4 EA 7425 HESPER, Health Services and Performance Research, Claude Bernard Lyon 1 University, Lyon, France

Corresponding author

\section{Nicolas Williet, MD}

Hepatogastroenterology Department, University Hospital of Saint-Etienne, Avenue Albert Raimond, Saint-Etienne 42270, France

Fax: +33-4-77828452

nwilliet@yahoo.fr

\section{Bibliography}

DOI https://doi.org/10.1055/a-0924-5380

Published online: 4.6.2019

Endoscopy 2019; 51: E335-E336

(C) Georg Thieme Verlag KG

Stuttgart · New York

ISSN 0013-726X

\section{ENDOSCOPY E-VIDEOS}

https://eref.thieme.de/e-videos

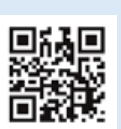

Endoscopy E-Videos is a free access online section, reporting on interesting cases and new techniques in gastroenterological endoscopy. All papers include a high quality video and all contributions are freely accessible online.

This section has its own submission website at https://mc.manuscriptcentral.com/e-videos 